\title{
INTEGRATED ASSESSMENT OF SOCIO-ECONOMIC POTENTIAL OF RURAL COMMUNITIES FOR DEVELOPMENT OF GREEN ECONOMY
}

\author{
Maria Tereshina ${ }^{1}$, Tatjana Tambovceva ${ }^{2}$, Aleksan Khalafyan ${ }^{1}$ \\ ${ }^{1}$ Kuban State University, Russia; ${ }^{2}$ Riga Technical University, Latvia \\ mwstepanova@mail.ru, tatjana.tambovceva@rtu.lv, khaliphyan@kubannet.ru
}

\begin{abstract}
Transition to the "green" economy is a complex and uneven process, which may not occur simultaneously in the entire social system. The stimuli for the development of the "green" economy emerge depending on the resource potential (tangible and intangible) and the actual conditions observed in concrete rural communities. The present research is dedicated to the development and approbation of the instruments for the recognition of the resource base of rural communities in the development of "green" economy. Theauthorssuggestanapproachbasedontheprinciplesofmultivariateanalysis, which allows analysts to identify "growth areas" of the green economy, to develop a new explanatory model of the process and results of the ecological transformation of rural economies, and to determine priorities for state support and the most attractive areas for private investment. In order to increase efficiency of state and private investment supporting "green" development of rural areas it is necessary to assess the existing "green" economy potential in the context of their current resource opportunities.
\end{abstract}

Keywords: green economy, multivariate analysis, rural communities, sustainable development.

\section{Introduction}

Rural areas are complex natural and economic systems, and their existence and wellbeing are greatly determined by close integration of natural, economic and social aspects. Green economy is an economy that results in improved human well-being and social equity, while significantly reducing environmental risks and ecological scarcities [1].

Green economy problems and solutions in different countries are extensively studied and analysed by UN, UNEP, European Commissions, governments, companies and researchers [2; 3].

Economy of the majority of rural communities is based on the agricultural production, which has a considerable negative impact on the environment. Extensive farming and widespread use of chemical fertilizers, the resulting reduction of biodiversity, negative impact caused on the agriculture by other areas of human activity lead to the degradation of agricultural lands, emergence of adverse external effects, as well as social, ecological and economic losses [4; 5].

A new "green" trend in the economic development of rural communities is currently emerging due to growing ecological concerns of the global economy [6]. "Green" economic policies bring substantial benefits not only in view of considerable dependence of rural economies on the industries sensitive to the change in the qualitative parameters of the environment, but also considering the employment of innovative solutions, the share of which is particularly high in energy-efficient and low-carbon technologies [7].

As illustrated by the international experience [8-11], development of the "green" economy in the rural areas allows maintaining and increasing productivity of the agricultural enterprises ensuring stable production, it also allows ensuring full employment of the rural population, decreasing adverse negative effects and gradually increasing positive effects, promoting rehabilitation of ecological resources and natural capital assets, decreasing pollution and facilitating more efficient resource use, sustaining traditions of the local rural communities uniting them with the development of rural, ecological and agro tourism.

Transition to the "green" economy is a complex and uneven process, which may not occur simultaneously in the entire social system. The stimuli for the development of the "green" economy emerge depending on the resource potential (tangible and intangible) and the actual conditions observed in concrete rural communities. The best practices can be further adopted by the entire society. Differences in the resource potential of rural communities condition the differences in the rate and quality of transition to the "green" economy and its possible scenarios at the level of particular local socio-economic systems. Assessment of the resource potential of the "green growth" of rural areas allows determining priorities for state support and the most attractive areas for private investment. 
The authors see the concept of potential of rural communities in the development of "green" economy as a complex indicator including the current resource opportunities and possible areas of their use in order to achieve additional social, economic, and ecological effects. The complex potential presents the total of the interrelated blocks formed as a result of the systemic interaction of external and internal factors, including in general terms physical resource potential, as well as social preparedness potential of the local communities for the development of "green" economy (sociopsychological, regulatory, methodological). The present research analyzes physical resources that provide the basis for the development of different areas of "green" economy in the rural areas as a research object.

The goal of this research is to develop and approbate the instruments for the recognition of the resource base of rural communities in the development of "green" economy. In order to reach this goal, the following objectives have been set:

- to determine and verify with expert assessment the system of quantitative indicators of the "green" economy development potential in the rural areas;

- based on the statistical-mathematical methods, to propose an approach to the assessment of the resource potential of rural areas, which allows evaluating the opportunities for its use based on the principles of "green growth" and determining priority areas for private investment and state support on the basis of a model region.

Novelty of the current research consists in substantiating the approach that allows determining potential "growth areas" of the "green" economy and developing a new explanatory model of the process and results of the ecological transformation of rural economies based on the principles of multivariate analysis. Topicality of the research is determined by the necessity to establish theoretical and methodological premises for the launch and expansion of "green" economy practices to ensure sustainable development of rural communities.

\section{Materials and methods}

In order to increase efficiency of state and private investment supporting "green" development of rural areas it is necessary to assess the existing "green" economy potential in the context of their current resource opportunities.

Resource potential of rural areas in the development of "green" economy was considered as the total of quantitative indicators selected and verified by expert survey conditionally divided into four blocks: natural-engineering, infrastructure, demographic, finance and investment. Assessment of the natural-engineering, infrastructure, demographic, and finance and investment potentials is performed on the basis of the system of quantitative indicators selected and verified by expert survey. The main criteria for the selection of quantitative indicators include recognition of the basic resources for the development of "green" economy, relevance of the objectives of ecological development, opportunity to manage resources at the local level, availability of the resource data, possibility to assess the resources based on the objective quantitative data.

The Krasnodar Region was selected as the object of the present research as one of the most developed agricultural regions of Russia, where agricultural land takes up more than $60 \%$ of the total area and rural population constitutes more than a half of the total population of the region. The choice of the region as a model can also be explained by the fact that there is a considerable natural resource potential for the development of renewable energy, ecological tourism, organic agriculture and other important areas of "green" economy.

The research comprised the total of 37 rural areas in the region, territorially "clustered" around definite administrative entities. "Green" economy development potential was assessed using the total of 19 quantitative indicators conditionally divided into four groups:

- natural-engineering potential indicators (total solar irradiance per unit area in the territory of the district, annual waste production, forest cover, agricultural land area, volume of pollutants emitted by all stationary sources);

- infrastructure potential indicators (the number of waste processing plants, mileage of public automobile roads of local significance owned by municipal entities at the end of the year, the share of public automobile roads of local significance that do not meet the statutory requirements 
in the total mileage of public automobile roads of local significance, the share of population in the residential areas that do not have regular bus (railway) connections with the administrative center in the total population, specific electric energy consumption in multi-apartment buildings per one inhabitant, specific thermal energy consumption in multi-apartment buildings per $\mathrm{m} 2$ of the total area, the number of accommodations in the collective accommodation facilities);

- demographic potential indicators (average annual resident population, working age population, natural population increase);

- finance and investment development potential indicators (local budget surplus/deficit, current environment protection expenses, volume of investment in fixed assets (except for budget subsidies) per person, the number of small and medium-sized enterprises per 10 thousand inhabitants).

Metric approach earlier proposed by the authors [12] was used to solve the multi-criteria arrangement problem to determine the rural areas most promising for the development of "green" economy.

\section{Results and discussion}

Such variety of indicators complicates the solution of the arrangement problem, as every rural area can lead with regard to some indicators and fall behind with regard to others. It should be pointed out that the majority of indicators (except for the share of public automobile roads of local significance that do not meet the statutory requirements and the share of population in the residential areas that do not have regular bus (railway) connections with the administrative center) are numerical quality criteria, i.e. their higher or lower values characterize the superiority margin of some territories over others.

In terms of multivariate statistical analysis, the analyzed rural areas are multi-dimensional objects $O_{i}(i=1, \ldots, 37)$, i.e. the points of the multidimensional space in the coordinate grid of indicators $Q_{1}, Q_{2}, \ldots, Q_{19}$, with coordinates $q_{i 1}, q_{i 2}, \ldots, q_{i 19}$. Arrangement of the objects (ranging) implies their comparison. In mathematical statistics, similarity (difference) between the objects is determined by calculation of the distances between them as the points of metric spaces [13].

The essence of the metric approach can be explained as follows. Let us present the values of the criteria $q i j, i=\overline{1, m} ; j=\overline{1, n}$ in the form of a grid (matrix) with the number of lines equal to the number of objects $m$, and the number of columns equal to $n$ (in our case $m=37, n=19$ ):

$$
Q=\left\{\begin{array}{c}
q_{11} q_{12}, \ldots, q_{1 n} \\
q_{21} q_{22}, \ldots, q_{2 n} \\
\ldots \\
q_{m 1} q_{m 2}, \ldots, q_{m n}
\end{array}\right\},
$$

The lines of the matrix correspond to the objects, the columns - to the criteria (in our case indicators). Criteria $Q j$ exhibits the property that if object $O k$ is preferable to object $O l$, then $q k j>($ or $<$ ) $q l j$. Sign " $>$ " is used in case the higher value of the criteria is preferable, sign " $<$ " is used if the lower value of the criteria is preferable.

In order to be able to range the objects, let us find the object with the best - either minimal or maximal-criteria values depending on the nature of their preference. If such object does not exist, let us introduce into the analysis a hypothetically best (ideal) object $O^{*}$ ideal with the best criteria values $q i * j=\overline{1, n} ; i=\overline{1, m}$

$$
q j^{*}=\max (\min )\{q i j\},
$$

Such "ideal" territory (IT) consolidates the best indicator values for all 37 territories - the highest values of all indicators, except for two above mentioned indicators, for which the lowest values have been selected.

Calculating pair distances between the objects $O 1, O 2, \ldots, O m, O^{*}$ ideal, we can not only easily assess their similarity, but also range them by distance to the reference object $O^{*}$ ideal based on the 
principle the smaller the distance, the higher is the rank. As the distances calculated using the input data can be considerably influenced by the differences in the units of measurement of the axes, in the calculations, the input data should be transformed into a non-dimensional form by standardizing the columns of matrix $Q$.

Denoting standardized values by $q_{j}{ }^{*}, q i j s$, the Euclidean distance $\rho i$ between the objects $O i$ and $O^{*}{ }^{*}$ deal can be easily calculated using formula (3):

$$
\rho i\left(O i, O_{i d e a l}^{*}\right)=\sqrt{\left(q_{i 1}^{s}-q_{1}^{s}\right)^{2}+\left(q_{i 2}^{s}-q_{2}^{s}\right)^{2}+\ldots+\left(q_{i n}^{s}-q_{n}^{s}\right)^{2}} .
$$

In order to range the objects, the calculated distances should be adjusted in the ascending order and ascribed ranks $1,2, \ldots, m$ corresponding to each value $\rho i$, and that means to each objectOi. The object with rank 1 will be the best, as it corresponds to the minimal distance.

Using the procedure of hierarchical classification of the module cluster analysis of software package STATISTICA [14] on the basis of the standardized data, pair Euclidean distances between the territories were calculated as the points of multi-dimensional (19 dimensions) space, which are presented in Table 1. The smallest distance -8.7 - was demonstrated by District 34 that was ranked first in the rating; District 31 with the distance 8.85 was ranked second; further - District 28, District 15 with the distance 13.69 was ranked last, taking the $37^{\text {th }}$ place.

Table 1

Results of ranging of rural areas by their "green"economy development potential

\begin{tabular}{|c|c|c|c|}
\hline Districts & № & Distanceto IT & Rank \\
\hline District 1 & 1 & 12.02 & 15 \\
\hline District 2 & 2 & 12.87 & 27 \\
\hline District 3 & 3 & 13.12 & 31 \\
\hline District 4 & 4 & 11.82 & 11 \\
\hline District 5 & 5 & 12.67 & 23 \\
\hline District 6 & 6 & 12.92 & 28 \\
\hline District 7 & 7 & 12.44 & 21 \\
\hline District 8 & 8 & 12.19 & 18 \\
\hline District 9 & 9 & 11.35 & 8 \\
\hline District 10 & 10 & 12.37 & 19 \\
\hline District 11 & 11 & 13.33 & 34 \\
\hline District 12 & 12 & 11.09 & 6 \\
\hline District 13 & 13 & 11.87 & 12 \\
\hline District 14 & 14 & 12.16 & 17 \\
\hline District 15 & 15 & 13.69 & 37 \\
\hline District 16 & 16 & 10.74 & 4 \\
\hline District 17 & 17 & 11.67 & 9 \\
\hline District 18 & 18 & 13.13 & 32 \\
\hline District 19 & 19 & 12.70 & 24 \\
\hline District 20 & 20 & 12.95 & 29 \\
\hline District 21 & 21 & 12.99 & 30 \\
\hline District 22 & 22 & 11.82 & 10 \\
\hline District 23 & 23 & 12.16 & 16 \\
\hline District 24 & 24 & 12.66 & 22 \\
\hline District 25 & 25 & 11.93 & 13 \\
\hline District 26 & 26 & 12.81 & 25 \\
\hline District 27 & 27 & 11.12 & 7 \\
\hline District 28 & 28 & 10.12 & 3 \\
\hline District 29 & 29 & 13.43 & 35 \\
\hline District 30 & 30 & 12.87 & 26 \\
\hline District 31 & 31 & 8.85 & 2 \\
\hline
\end{tabular}


Table 1 (continued)

\begin{tabular}{|c|c|c|c|}
\hline Districts & № & Distanceto IT & Rank \\
\hline District 32 & 32 & 10.88 & 5 \\
\hline District 33 & 33 & 12.43 & 20 \\
\hline District 34 & 34 & 8.70 & 1 \\
\hline District 35 & 35 & 13.26 & 33 \\
\hline District 36 & 36 & 11.94 & 14 \\
\hline District 37 & 37 & 13.48 & 36 \\
\hline
\end{tabular}

The grid (matrix) of the distances between the objects may provide more precise data on the structure of similarities and differences among them. Hierarchical clustering is the most widely known method of representation of distance matrix; it is based on the principle of tree diagram, or tree diagram, which provides a graphic representation of the results of consecutive grouping of the objects into homogeneous groups (clustering).

\section{Tree Diagram for 38 Cases \\ Complete Linkage \\ Euclidean distances}

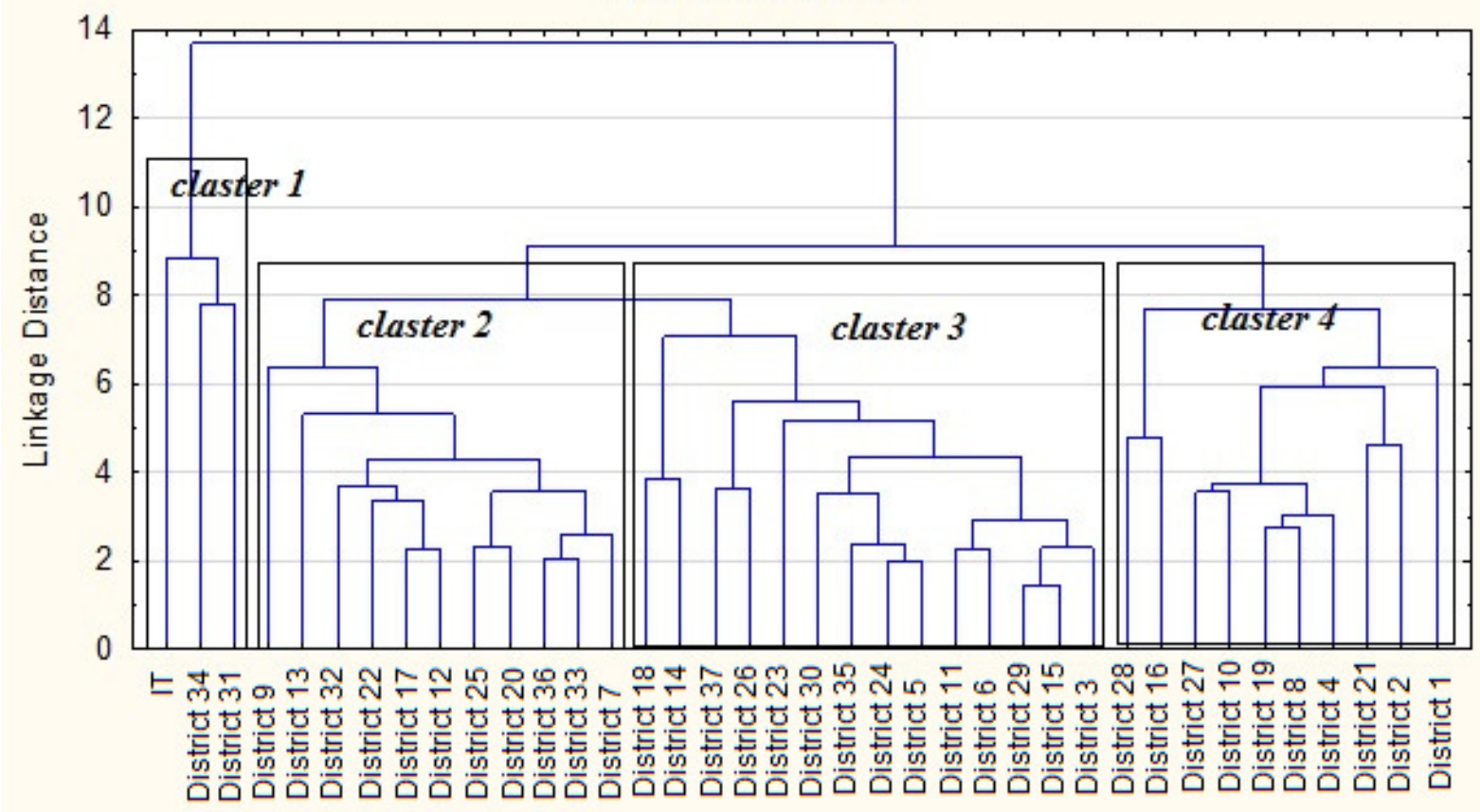

Fig. 1. Tree diagramoftheclustering of rural areas by total of indicators of "green" development potential

It follows from the Tree diagram in Fig. 1 (distances of territorial conglomerations are set on OY axis), which was built using the complete link method, that initially a homogeneous group (cluster) is formed by District 29 and District 15, as there is the smallest distance between them (less than 2), which indicates the greatest similarity. These districts take close positions in the rating, $35^{\text {th }}$ and $37^{\text {th }}$ place, respectively. Further, great similarity is demonstrated by District 24 and District 5, the distance between them equals 2 , they also take close positions in the rating, $22^{\text {nd }}$ and $23^{\text {rd }}$ place, respectively. There is a great similarity between District 36and District 33, which also form a cluster, the distance between them slightly exceeds 2 , they also take close positions in the rating, $14^{\text {th }}$ and $20^{\text {th }}$ places, respectively, and so on. As it can be seen from the Tree diagram, successive increase of the distance leads to the successive addition of other municipal entities to the formed clusters. It can be noticed that at the distance close to 8 four homogeneous (similar) groupsof territories were formed based on the total of 19 considered indicators - clusters 1, 2, 3, 4. It is interesting to note that the leaders of the rating - District 34, District 31, and "ideal" territory (IT) - were included in cluster 4 (resource-rich territories). 


\section{Conclusions}

"Green" economy practices are a catalyst for investment and innovation, which do not only offer new economic opportunities for rural communities, but also provide the basis for structural changes towards resource efficient, technologically advanced industries and business activities.

Ranking of the rural areas performed in connection to administrative entities on the basis of multivariate analysis allowed at a first approximation determining four basic clusters (resource-rich, medium resource-rich, resource-poor and resource deficient territories). In order to further update the forecasting instruments it is necessary to conduct a detailed recognition of the resource base of rural areas in the resource-rich and medium resource-rich clusters (clusters 3 and 4 in the Tree diagram), to identify priority areas and the main "bottlenecks" of the development of "green" economy. Given that, identification of the deficit type of resources would allow determining the areas and methods of administrative impact on the development of "green" economy at the local level. Concrete indicators of the assessment of the "green" economy potential may potentially require updating and clarification to account for the concrete conditions, however, the authors suppose that the approach proposed within the present research in general terms may illustrate the opportunities it offers.

In our opinion, in order to develop such eco-loci or "growth areas" of the "green" economy in the local rural communities of the Krasnodar Region, it is necessary:

1. To establish the institutional basis for the development of "green" economy at the federal and regional level;

2. To attract investment to ecology-oriented projects in the rural areas. To successfully implement the intended tasks, the system of preferential taxation should be established, and informative and administrative support of ecology-oriented investment projects should be ensured.

3. To create and recreate the demand for "green" goods and services supplied by the rural areas, to develop ecological culture and ecological awareness, to implement training and informative programs and organize events to ensure producers and consumers gain the necessary knowledge, skills and motivation for the development of "green" economy.

4. To subsidize organic agriculture, also at the expense of decreasing subsidies to traditional intensive land use, to allocate compensations for the development and maintenance of the ecologically safe types of business activity.

\section{Acknowledgements}

The research was carried out with the support of the RFBR project No. 16-32-0016 "The development of a mechanism for implementing the concept of a "green" economy in local practices of the domestic communities".

\section{References}

[1] What does green economy mean? UNECE [online] [15.01.2018]. Availableat: https://www.unece.org/sustainable-development/green-economy/what-does-green-economymean.html

[2] A guidebook to the Green Economy. Issue 1: Green Economy, Green Growth, and Low-Carbon Development - history, definitions and a guide to recent publications. Division for Sustainable Development, UNDESA.[online] [28.01.2018]. Available at: https://sustainabledevelopment.un.org/content/documents/GE \%20Guidebook.pdf

[3] Green economy in action: Articles and Excerpts that Illustrate Green Economy and Sustainable Development Efforts [online] [28.01.2018]. Available at: http://www.un.org/waterforlifedecade/pdf/green_economy_in_action_eng.pdf

[4] Rey Benayas, J.M., Bullock, J.M. Restoration of Biodiversity and Ecosystem Services on Agricultural Land. Ecosystems. Vol.15, no. 6,2012, pp. 883-899.

[5] Karunarathna, M., Wilson, C. Agriculturalbiodiversityandfarmleveltechnicalefficiency: Anempiricalinvestigation. JournalofForestEconomics. Vol. 29, part A, 2017, pp. 38-46.

[6] Конференция «Зелёное финансирование для устойчивого развития» станет вкладом России в решения «Группы двадцати» под председательством Германии (Conference "Green financing for sustainable development" will be Russia's contribution to the decisions of the G20 under the chairmanship of Germany) [online] [18.05.2017]. Available at: 
http://www.mnr.gov.ru/press/news/konferentsiya_zelyenoe_finansirovanie_dlya_ustoychivogo_ra zvitiya_stanet_vkladom_rossii_v_resheniya_/?sphrase_id=7406 (In Russian)

[7] ТерёшинаМ.В., ФедороваЮ.С. «Зеленаяэкономика»: перспективы, выгодыирискидляустойчивогоразвитиярегиона (“GreenEconomy”: Prospects, Benefitsand Risks forSustainableDevelopmentoftheRegion). Экономика устойчивого развития. 2012. № 9. pp. 189-195. (In Russian)

[8] Melece, L. Environmentally Friendly Agriculture: Development Issues in Latvia. Socialiniaityrimai/ SocialResearch. 2010.Nr.2 (19), pp. 37-46.

[9] Green Economy Opportunities For Rural Europe. Luxembourg: Publications Office of the European Union, [online] [15.01.2018]. Available at: https://enrd.ec.europa.eu/sites/enrd/files/publi-enrd-rr-23-2017-en.pdf

[10] From Green Economies to Green Societies. UNESCOs Commitment to Sustainable Development [online] [15.01.2018]. Availableat:http://unesdoc.unesco.org/images/0021/002133/213311e.pdf

[11]Transition to the Green Economy. European Network for Rural Development[online] [16.01.2018]. Available at: https://enrd.ec.europa.eu/thematic-work/greening-ruraleconomy/transition-green-economy_en

[12]Халафян А.А., Шевченко И.В. Составление и оценка согласованности банковских рейтингов средствами компьютерного анализа (Compilation and assessment of bank rating coherence by means of computer analysis). Финансы и кредит. 2017. Т. 23. № 28 (748). pp. 1655-1677. (In Russian)

[13] Hill T., Lewicki P. Statistics methods and applications. StatSoft, Tulsa, OK,2007. 719 p.

[14]Халафян A.A. STATISTICA 6. Статистический анализ данных (STATISTICA 6. Statisticalanalysisofdata). М: Бином, 2010. 528 c. (In Russian) 